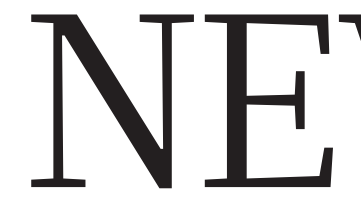

ASTRONOMY All eyes on the Milky Way's turbulent centre $\mathbf{p . 2 9 6}$
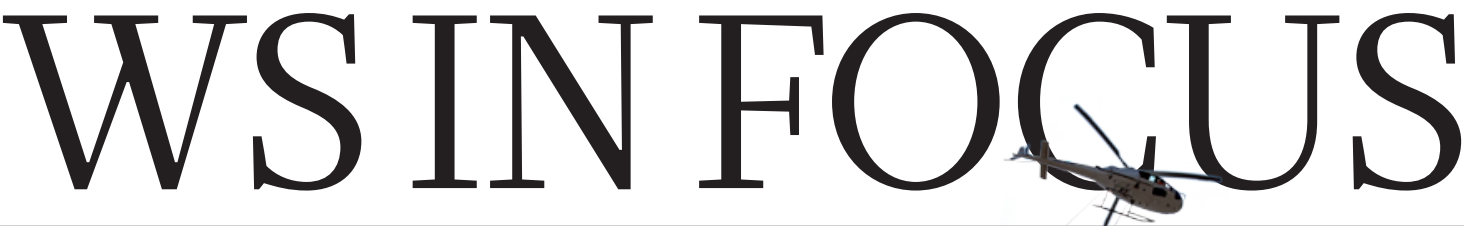

GENOMICS Chinese project probes the genes of genius $\mathbf{p . 2 9 7}$
PoLITICS Stephen Hawking provokes war of words over Israel boycott p.299
CONSERVATION A rain of death for invasive Galapagos rats $\mathbf{p . 3 0 6}$

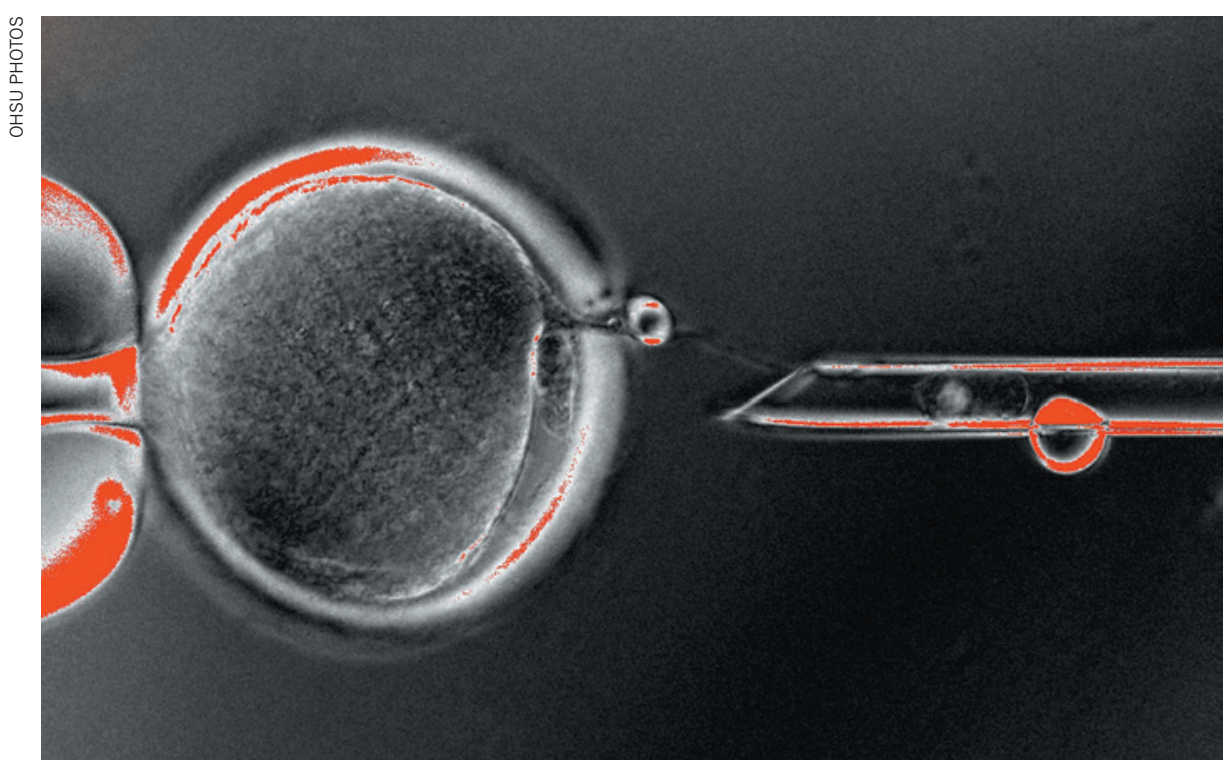

Seeing double: human embryonic stem cells have finally been made using cloning techniques.

\title{
Human stem cells created by cloning
}

Breakthrough sets up showdown with induced adult lines.

\section{BY DAVID CYRANOSKI}

$\mathrm{I}$ $\mathrm{t}$ was hailed some 15 years ago as the great hope for a biomedical revolution: the use of cloning techniques to create perfectly matched tissues that would someday cure ailments ranging from diabetes to Parkinson's disease. Since then, the approach has been enveloped in ethical debate, tainted by fraud and, in recent years, overshadowed by a competing technology. Most groups gave up long ago on the finicky core method - production of patient-specific embryonic stem cells (ESCs) from cloning. A quieter debate followed: do we still need 'therapeutic' cloning?

A paper published this week ${ }^{1}$ by Shoukhrat Mitalipov, a reproductive biology specialist at the Oregon Health and Science University in Beaverton, and his colleagues is sure to rekindle that debate. Mitalipov and his team have finally created patient-specific ESCs through cloning, and they are keen to prove that the technology is worth pursuing.

Therapeutic cloning, or somatic-cell nuclear transfer (SCNT), begins with the same process used to create Dolly, the famous cloned sheep, in 1996. A donor cell from a body tissue such as skin is fused with an unfertilized egg from which the nucleus has been removed. The egg 'reprograms' the DNA in the donor cell to an embryonic state and divides until it has reached the early, blastocyst stage. The cells are then harvested and cultured to create a stable cell line that is genetically matched to the donor and that can become almost any cell type in the human body.

Many scientists have tried to create human SCNT cell lines; none had succeeded until now. Most infamously, Woo Suk Hwang of Seoul National University in South Korea used hundreds of human eggs to report two successes, in 2004 and 2005. Both turned out to be fabricated. Other researchers made some headway. Mitalipov created SCNT lines in monkeys ${ }^{2}$ in 2007. And Dieter Egli, a regenerative medicine specialist at the New York Stem Cell Foundation, successfully produced human SCNT lines ${ }^{3}$, but only when the egg's nucleus was left in the cell. As a result, the cells had abnormal numbers of chromosomes, limiting their use.

\section{MONKEYING AROUND}

Mitalipov and his group began work on their new study last September, using eggs from young donors recruited through a university advertising campaign. In December, after some false starts, cells from four cloned embryos that Mitalipov had engineered began to grow. "It looks like colonies, it looks like colonies," he kept thinking. Masahito Tachibana, a fertility specialist from Sendai, Japan, who is finishing a 5-year stint in Mitalipov's laboratory, nervously sectioned the 1-millimetre-wide clumps of cells and transferred them to new culture plates, where they continued to grow - evidence of success. Mitalipov cancelled his holiday plans. "I was happy to spend Christmas culturing cells," he says. "My family understood."

The success came through minor technical tweaks. The researchers used inactivated Sendai virus (known to induce fusion of cells) to unite the egg and body cells, and an electric jolt to activate embryo development. When their first attempts produced six blastocysts but no stable cell lines, they added caffeine, which protects the egg from premature activation.

None of these techniques is new, but the researchers tested them in various combinations in more than 1,000 monkey eggs before moving on to human cells. "They made the right improvements to the protocol," says Egli. "It's big news. It's convincing. I believe it."

The experiments took only a few months, Mitalipov says. "People say, you did it in monkeys in 2007. Why did it take six years in humans?" Most of the time, he says, was spent navigating US regulations on embryo research.

The researchers carried out a battery of tests to prove that their SCNT cells could form various cell types, including heart cells that 
- are able to contract spontaneously.

Their first cell lines were created using fetal skin cells; others were derived using donor cells from an 8-month-old patient with a rare metabolic disorder called Leigh syndrome, to prove that ESCs could be made from more mature donor cells. The technique does not require prohibitive numbers of eggs: it took 15 from one donor to produce one cell line and 5 from a different donor to make another. "The efficiency was the most impressive thing," says George Daley, a stem-cell expert at Children's Hospital Boston in Massachusetts.

Such improvements might be necessary to convince people that SCNT research is still worthwhile. Egg donors for the experiment received US\$3,000-7,000 in compensation. This is expensive and, according to some bioethicists, risks creating an organ trade that preys on the poor. Because the technique requires the destruction of embryos, funds from the US National Institutes of Health (NIH) cannot be used to make or study SCNTderived cell lines, hampering further clinical research. (Mitalipov maintains a separate laboratory for NIH-funded research.)

Public fears that the technology might be used to create human clones are another sticking point. The research might spark "cloning hysteria" that opponents of stem-cell research could capitalize on, says Bernard Siegel, executive director of the Genetics Policy Institute in Palm Beach, Florida. But Mitalipov has tried without success for more than a decade to produce a monkey by cloning. Tachibana says that an upcoming publication will explain why reproductive cloning of humans is not possible using their SCNT technique.

Still, Daley and most other stem-cell researchers have shifted to another method for creating genetically matched, patientspecific cell lines: reprogramming adult cells to an embryonic state to produce induced pluripotent stem (iPS) cells. First reported in 2006, the technique does not involve eggs, cloning or destruction of embryos . "Honestly, the most surprising thing [about this paper] is that somebody is still doing human [SCNT] in the era of iPS cells," says Miodrag Stojkovic, who studies iPS cells for regenerative medicine and runs a fertility clinic in Leskovac, Serbia.

But Stojkovic, like others, awaits the results of head-to-head comparisons between iPS and SCNT cells. Some research has shown that iPS cells are not completely reprogrammed and that stem cells derived from SCNT are more like embryonic stem cells derived from in vitro fertilization. Mitalipov and Tachibana are now conducting a study to compare iPS cells and SCNT cells derived from the same donor cell. "These results," says Daley, "will be fascinating." -

1. Tachibana, M. et al. Cell http://dx.doi. org/10.1016/j.cell.2013.05.006 (2013)

2. Byrne, J. A. et al. Nature 450, 497-502 (2007)

3. Noggle, S. et al. Nature 478, 70-75 (2011).

4. Takahashi, K. \& Yamanaka, S. Cell 126, 663-676 (2006).

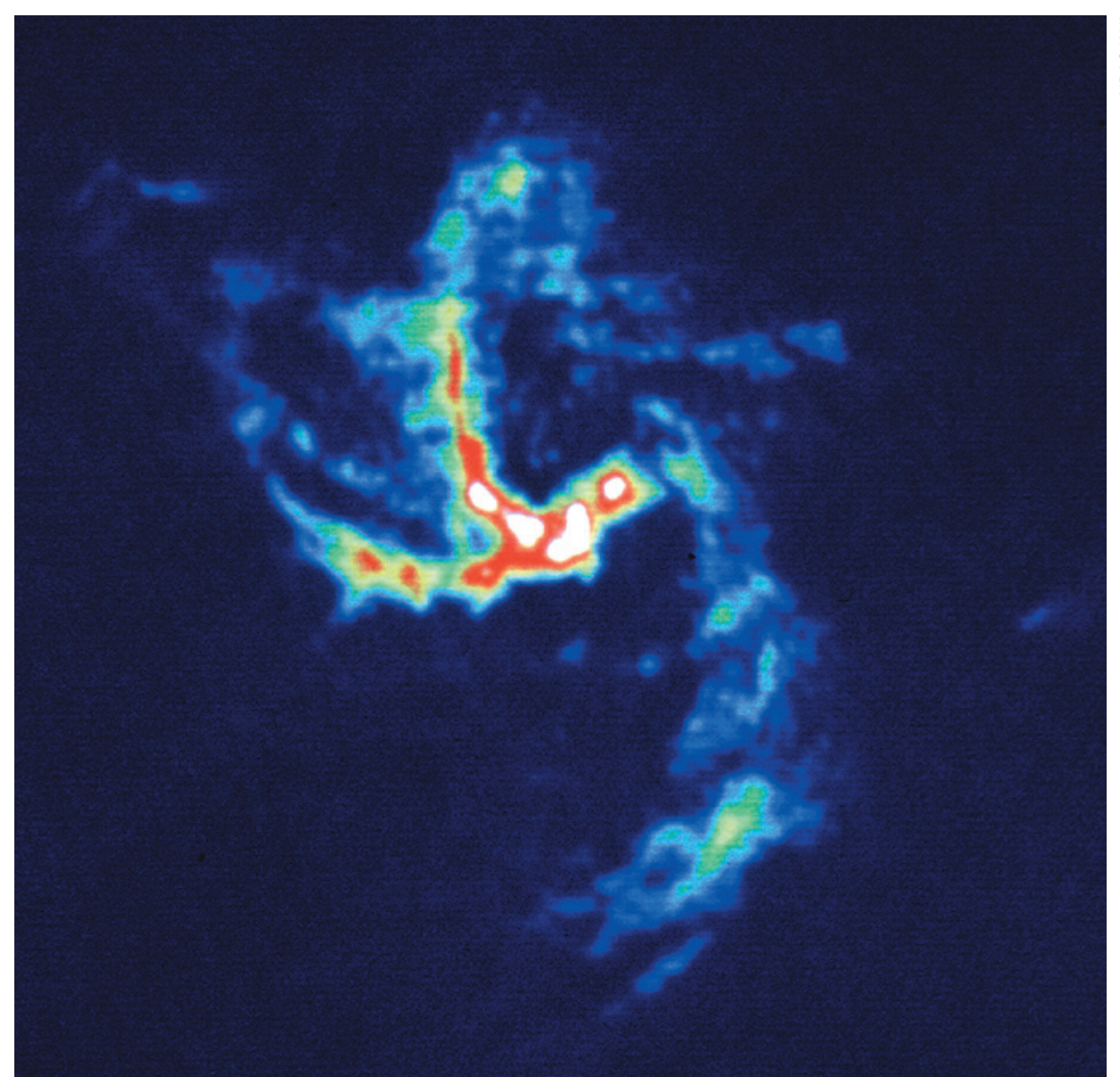

Gas clouds swirl around the black hole at the Milky Way's centre (seen here in radio emission).

\section{ASTRONOMY}

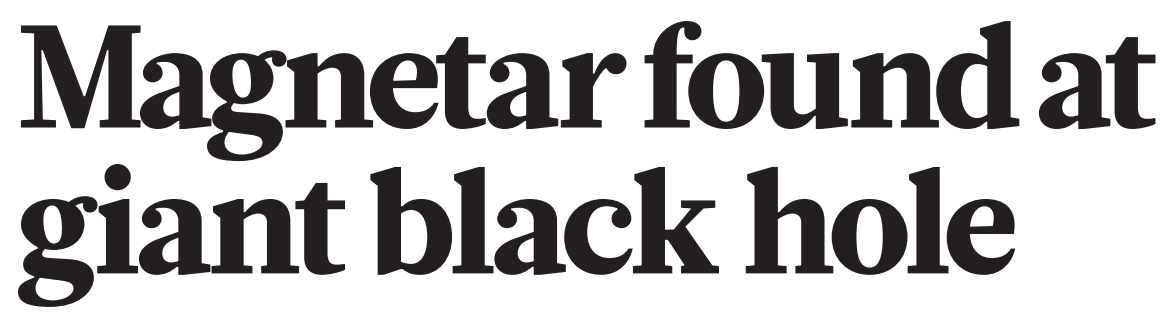

Magnetized neutron star could test Einstein's theory.

\section{BY EUGENIE SAMUEL REICH}

$\longrightarrow$ ale Frail couldn't resist the prospect of watching a black hole swallow its prey. Frail, who is in charge of the Very Large Array (VLA) of radio telescopes near Socorro in New Mexico, had seen a report last month about a long-lived X-ray flare emanating from the centre of the Milky Way, home to a supermassive black hole called Sagittarius $A^{\star}\left(\operatorname{Sgr~} A^{*}\right)$. Astronomers were speculating that the flare might be a sign that a gas cloud they had been tracking had begun its death spiral into the black hole.

Frail was sceptical. The cloud's death was not expected until between September this year and March 2014. But Frail did not want to risk missing the action. Within hours of seeing the report, he had trained the VLA's radio dishes on the scene, only to find nothing remarkable. Frail was puzzled. If the flare wasn't the arrival of the gas cloud, what was it?

An answer soon came from other telescopes watching the drama at the centre of the Galaxy: the flare was coming from a magnetar, a highly magnetized kind of pulsar, or rotating neutron star. Its position near Sgr A* makes it a precious find. The magnetar's regular radio pulses could be used to measure the warping of space-time near the monster black hole and to test predictions of Einstein's general theory of relativity.

"There's huge interest in finding pulsars $\rightarrow$ NATURE.COM For more on the Milky Way's black hole, see: go.nature.com/apzhzf around supermassive black holes, and this is the first example," says Geoffrey Bower, a radioastronomer at the University of 